\title{
LEVANTAMENTO SOBRE O TIPO E USO DE MAQUINÁRIOS AGRÍCOLAS DOS PRODUTORES RURAIS NO MUNICÍPIO DE TAQUARUÇU DO SUL, RS
}

\section{Carla Janaina Werner ${ }^{1}$, Vanderlei Rodrigues da Silva ${ }^{2}$, Thais Pollon Zanatta ${ }^{3}$,} Rossano Feron Dagios ${ }^{3}$, Reginaldo Miguel Schaefer ${ }^{3}$

1 Acadêmica do curso de Agronomia da Universidade Federal de Santa Maria campus Frederico Westphalen (carli.werner@hotmail.com) Frederico Westphalen-

\author{
RS. Brasil
}

2 Professor Doutor do curso de Agronomia da Universidade Federal de Santa Maria campus Frederico Westphalen

3 Acadêmico (a) do curso de Agronomia da Universidade Federal de Santa Maria campus Frederico Westphalen

Recebido em: 08/09/2015 - Aprovado em: 14/11/2015 - Publicado em: 01/12/2015 DOI: http://dx.doi.org/10.18677/Enciclopedia_Biosfera_2015_186

\begin{abstract}
A agricultura familiar é característica do Médio Alto Uruguai, assim para auxiliar no crescimento e desenvolvimento rural torna-se claro e importante à utilização da mecanização agrícola. A redução do êxodo rural nessa região tem sido um dos maiores desafios, seguido pelo desenvolvimento local. Para que isso seja possível, torna-se necessário conhecer a realidade sobre o assunto e buscar capacitação de técnicos e produtores. Com base nisso, o objetivo do presente trabalho foi efetuar uma apuração sobre os equipamentos agrícolas que cada propriedade possui e a idade dos mesmos no município de Taquaruçu do Sul, RS. O estudo foi executado pelos acadêmicos integrantes do grupo PET Ciências Agrárias/FW em parceria com a Emater/ASCAR de Taquaruçu do Sul, onde foram entrevistados 113 propriedades de agricultores familiares, através de questionários estruturados. As questões relacionaram-se com os tipos de maquinários presentes na propriedade e as suas respectivas idades. Com isso, pode-se concluir que o nível tecnológico provindo dos maquinários e do seu tempo de aquisição se relaciona totalmente com o tipo de agricultura exercida na propriedade. Percebe-se que as propriedades da agricultura familiar precisam de incentivos para o fortalecimento e mantença da sua atividade agrícola, para assim garantir o desenvolvimento regional.
\end{abstract}

PALAVRAS-CHAVE: agricultura familiar, levantamento, propriedade, uso dos maquinários.

\section{SURVEY ON THE USE OF TYPE AND AGRICULTURAL MACHINERY OF RURAL PRODUCERS IN THE MUNICIPALITY TAQUARUÇU DO SUL, RS}

\begin{abstract}
Family farming is characteristic of Médio Alto Uruguai, as well to assist in the growth and rural development becomes clear and important use of agricultural mechanization. The reduction of rural migration in this region has been a major challenge, followed by local development. For this to be possible, it is necessary to
\end{abstract}


know the reality about it and seek training of technicians and producers. Based on this, the objective of this work was to make a determination on farm equipment that each property has and the age of them in the city of Taquaruçu do Sul, RS. The study was performed by intregrantes academic group PET Ciências Agrárias/ FW in partnership with Emater/ASCAR Taquaruçu do Sul to interview 113 properties from family farmers, through structured questionnaires. The questions were related to the types of machinery present on the property and their ages. Thus, it can be concluded that the technological level stemming from the machinery and its acquisition time is related to the type of totally exerted on the agricultural property. It is noticed that the properties of the family farmers need incentives for the strengthening and maintenance of their agricultural activity in order to guarantee regional development.

KEYWORDS: family farming, survey, property, use of machinery.

\section{INTRODUÇÃO}

O Brasil vem crescendo nos últimos anos e nos dias de hoje, o país é um dos maiores responsáveis pela produção de alimentos de todo o mundo. Dentre os setores agrários brasileiros, a agricultura familiar tem tomado importância na produção de alimentos para subsistência e oferta de empregos, além de ser fator redutor do êxodo rural. No entanto, para se obter uma produção adequada na busca da crescente demanda por alimentos e na qualidade desejada, é inevitável adquirir alternativas para otimizar as formas de cultivos existentes, a mecanização é um importante fator a ser considerado (OLIVEIRA \& PEREIRA, 2010).

Com o intuito de tecnificar as propriedades rurais, os agricultores demonstram a pretensão de mecanizar as propriedades. Contudo a aquisição de máquinas acaba alterando o retrato econômico-financeiro e toda a dinâmica de produção (NEVES et al., 2013). Apesar dessa menor incorporação de tecnologias, a Agricultura Familiar tem cada vez mais destaque no desenvolvimento agrícola do País, sendo que no Brasil, 4.367.902 estabelecimentos de agricultura familiar foram identificados, os quais representam $84,4 \%$ do total de estabelecimentos, mas ocupam apenas $24,3 \%$ da área total das propriedades (MUNDO EDUCAÇÃO, 2015).

O município de Taquaruçu do Sul fica situado geograficamente no norte do estado do Rio Grande do Sul, região esta denominada pelo Conselho Regional de Desenvolvimento de "Médio Alto Uruguai", com parcela significativa da população residindo no meio rural. Outra característica relevante da região é quanto ao relevo, que possui superfícies irregulares e altitudes que variam entre 400 a $800 \mathrm{~m}$. Essas formas de relevo não permitem mecanização em toda a extensão da área do Médio Alto Uruguai, ocorrendo apenas nas propriedades localizadas nas áreas mais planas (CIDADES BRASIL, 2015).

A mecanização agrícola está presente em 120.000 propriedades agrícolas do Estado do Rio Grande do Sul. As propriedades de agricultura familiar com mecanização chegam a 105.000 com 125.000 tratores com menos de $100 \mathrm{cv}$ (EMATER, 2015). A mecanização facilitou as operações de preparo do solo, plantio, colheita, preparo de forragem para os animais e outras atividades, que provocaram uma melhoria na qualidade de vida dos produtores e estimulado a permanência de jovens no meio rural (EMATER, 2015). Além disso, a mecanização aumenta a produtividade das áreas de produção, mas também tem outros benefícios como preservação de matas, reutilização de áreas degradadas, incentivo à diversificação da produção e a manutenção do pequeno produtor na atividade rural (OLIVEIRA \& PEREIRA, 2010). Apesar do uso de máquinas na atividade rural ter se tornado um 
elemento facilitador do trabalho, nem sempre a adoção de certas tecnologias é assumida por agricultores familiares que muitas vezes possuem um acesso limitado a esses benefícios.

Muitos agricultores pretendem mecanizar as propriedades, contudo a introdução de máquinas na exploração altera o retrato econômico-financeiro e a dinâmica da exploração. Vários determinantes da adoção e difusão tecnológica têm sido apresentados em estudos de economia e sociologia rural. Os mais comuns são: tamanho da propriedade, risco e incerteza, capital humano, forma de domínio sobre a terra, disponibilidade de crédito, trabalho e outros insumos (FILHO et al., 2011).

O baixo nível tecnológico da agricultura praticada pelos agricultores familiares brasileiros não pode ser explicado apenas pela falta de tecnologia adequada; ao contrário, em muitos casos, mesmo quando a tecnologia está disponível, esta não se transforma em inovação devido à falta de capacidade e condições para inovar (BATALHA et al., 2005).

Destaca-se a importância dos pequenos produtores de pensar e agir em grupo, isto é, por meio de associações e cooperativas, para dar viabilidade à aquisição coletiva, não só de máquinas e equipamentos, mas também de insumos e serviços. Dessa forma a mecanização agrícola terá viabilidade e poderá ser adotada amplamente pela Agricultura Familiar, melhorando a renda e a qualidade de vida no campo. Dentro desse contexto, o objetivo deste artigo foi realizar o levantamento da realidade da mecanização agrícola dos produtores do município de Taquaruçu do Sul, evidenciando aspectos às formas de tração, idade dos implementos e maquinários.

\section{MATERIAL E MÉTODOS}

O estudo foi realizado por acadêmicos e participantes do Grupo PET Ciências Agrárias/FW, do curso superior de Agronomia da Universidade Federal de Santa Maria (UFSM), campus Frederico Westphalen, RS, em parceria com a Empresa de Assistência Técnica e Extensão Rural (EMATER) do município de Taquaruçu do Sul, RS, no ano de 2011, com o objetivo de realizar o Mapeamento Agrícola (MapAgro) do município.

O município de Taquaruçu do Sul está localizado ao norte do estado do Rio Grande do Sul, na região que compreende o COREDE Médio Alto Uruguai. Possui aproximadamente $76,849 \mathrm{~km}^{2}$, sendo suas coordenadas de referência $27^{\circ} 25^{\prime} \mathrm{S}$ e 2327' O, com altitude média de $545 \mathrm{~m}$. As atividades desenvolvidas na região são essencialmente agrícolas, em torno de $60,7 \%$ da população está no meio rural (BRASIL, 2010).

A atividade agropecuária do município caracteriza-se como familiar, pois é exercida em pequenas propriedades, onde executam diversas atividades. Outra característica importante é a diversidade das atividades executadas dentro das propriedades rurais. Pode-se citar: cultivo de frutíferas, mandioca, feijão, trigo, soja, milho e erva-mate. Outra atividade de grande importância para a economia das propriedades e para o município é a produção leiteira. O conjunto das atividades agrícolas tem papel importante no Produto Interno Bruto (PIB) do município (BRASIL, 2010).

O levantamento dos dados foi realizado utilizando um questionário estruturado, constituído por 22 questões fechadas, de forma que permitissem respostas simples, caracterizando assim, os equipamentos agrícolas usados na propriedade rural. Foram entrevistadas 113 agricultores que compuseram a amostra 
final. As questões estavam relacionadas ao tipo e uso de maquinários agrícolas nas diversas atividades desempenhadas nas propriedades rurais desse município.

Os dados foram analisados e organizados com o auxilio do programa SigmaPlot 10.0 .

\section{RESULTADOS E DISCUSSÃO}

Os sistemas mecanizados agrícolas, depois da terra, representam o maior investimento para uma propriedade agrícola, podendo atingir até $28 \%$ do custo de produção (CONAB, 2006). De acordo com as entrevistas realizadas junto aos agricultores familiares, pode-se destacar a presença relevante de equipamentos de tração animal para a execução de tarefas diárias. Na Figura 1, pode-se verificar a presença de grades de tração animal em $99 \%$ das propriedades, bem como capinadeira $(90 \%)$ e semeadora $(71 \%)$. Na mesma figura pode-se ainda observar que algumas dessas propriedades possuem também equipamentos de tração mecânica como semeadora, em $96 \%$ das propriedades, grades e arados em $77 \%$ e $83 \%$ das propriedades familiares, respectivamente.

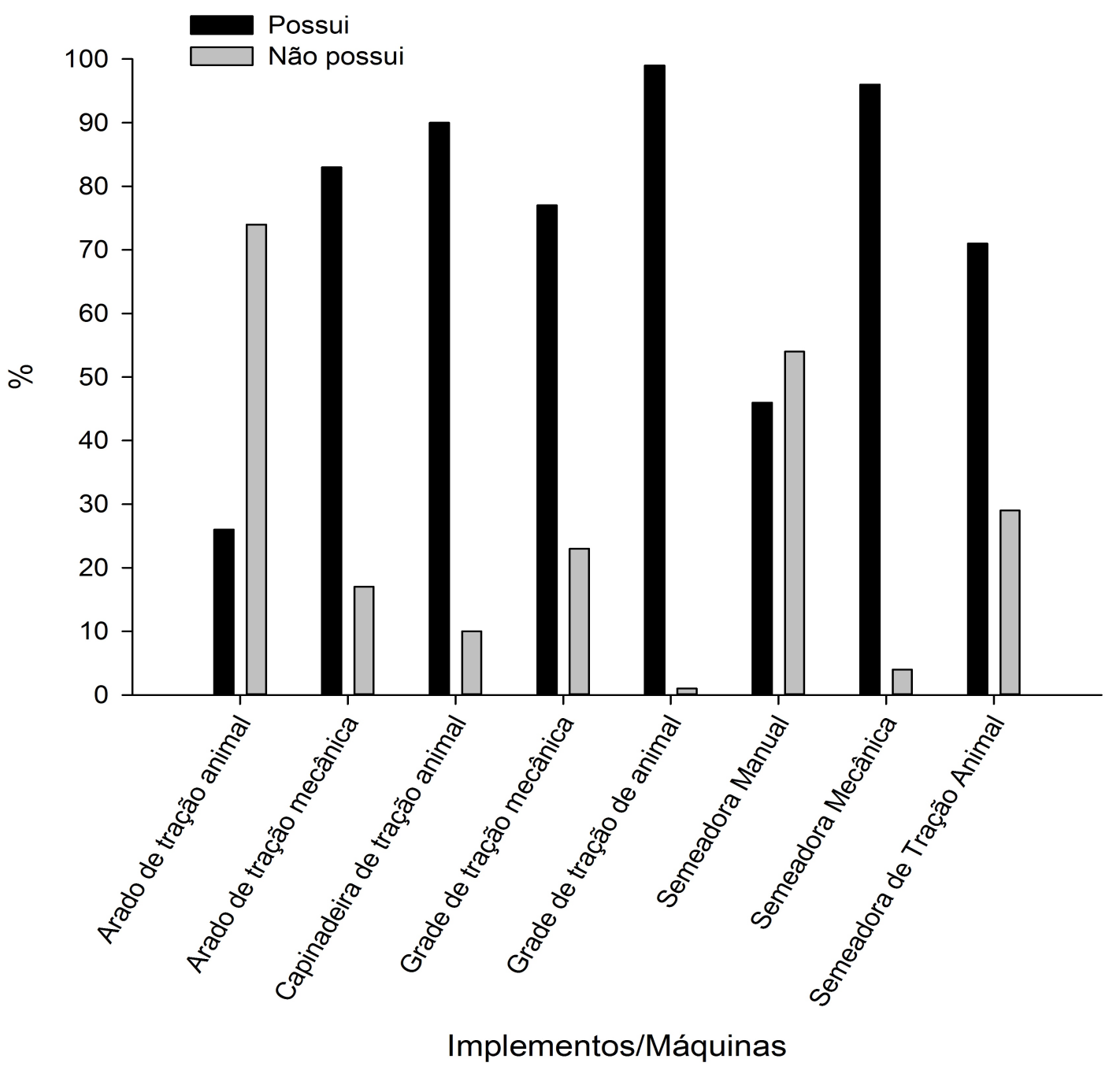

FIGURA 1 Relação percentual dos equipamentos agrícolas utilizados por agricultores familiares para o preparo de solo no município de Taquaruçu do Sul/RS 
Quanto ao uso do arado de aivecas e da grade agrícola de dentes, esses implementos estão vinculados, principalmente, ao tipo de tração disponível na propriedade. Em relação a outras máquinas, $54 \%$ dos entrevistados utilizavam semeadoras manuais (popularmente conhecidas como saraquás) para realizar as operações de semeadura. Sabe-se que essa operação requer maior esforço físico e tempo para ser executada, diminuindo a eficiência operacional do trabalho agrícola, destacando que este tipo de máquina é muito presente em pequenas propriedades familiares. Outro aspecto é a falta de máquinas específicas para adubação e tratamentos culturais, o que poderia tornar a atividade mais rentável e viável para o pequeno produtor.

Alguns fatores são muito relevantes no fato dos agricultores ainda usarem implementos de tração animal. Áreas de terras pequenas e com relevo declivoso dificultam a mecanização. Por outro lado observa-se que muitas propriedades já estão se mecanizando e adquirindo implementos de tração mecânica principalmente nos últimos anos.

Para BERETTA (1988) a área ideal para tração animal desde a aração até o cultivo está limitada a 5 ha, podendo considerar que até 15 ha a tração animal pode ser usada economicamente nas fases de plantio e cultivo. Esse mesmo autor recomenda o uso integral de trator nas operações agrícolas só em lavouras acima de 15ha. Isso vem de encontro com a realidade encontrada no município, onde maioria das famílias possuem pequenas áreas de terra, tendo que otimiza o uso dessa.

Um conjunto de fatores de natureza diversa, envolvendo desde fatores de natureza macroeconômica, especificação das tecnologias, até características particulares dos agricultores familiares, parece explicar as dificuldades enfrentadas por esse segmento para ampliar sua base tecnológica no mesmo ritmo registrado para a agricultura geral (FILHO et al., 2015).

A aquisição de implementos atualmente tem sido incentivada por programas como o Pronaf Mais Alimentos, que se constitui em uma ação estruturante que permite que produtores rurais invistam na modernização da infraestrutura produtiva de propriedades familiares (BRASIL, 2015). Deve-se tomar cuidado ao esse tipo de investimento, pois alguns agricultores têm produção em escala muito pequena o que reduz a capacidade de pagamento, sendo assim o investimento pode certas vezes causar o endividando dos produtores rurais. A associação entre pequenos produtores para a aquisição e uso em conjunto desses equipamentos pode ser uma solução para facilitar o trabalho agrícola.

Como pode ser verificado na Figura 2, nas propriedades rurais em estudo há a carência de máquinas essenciais para o cultivo do solo, quando perguntados $74 \%$ dos agricultores entrevistados responderam não possuir trator. Além disso, $97 \%$ dos agricultores familiares não possuem caminhão para escoar a produção agrícola. Pode-se verificar que a presença de automóveis (52\%) ocorre em pouco mais da metade das propriedades visitadas. 


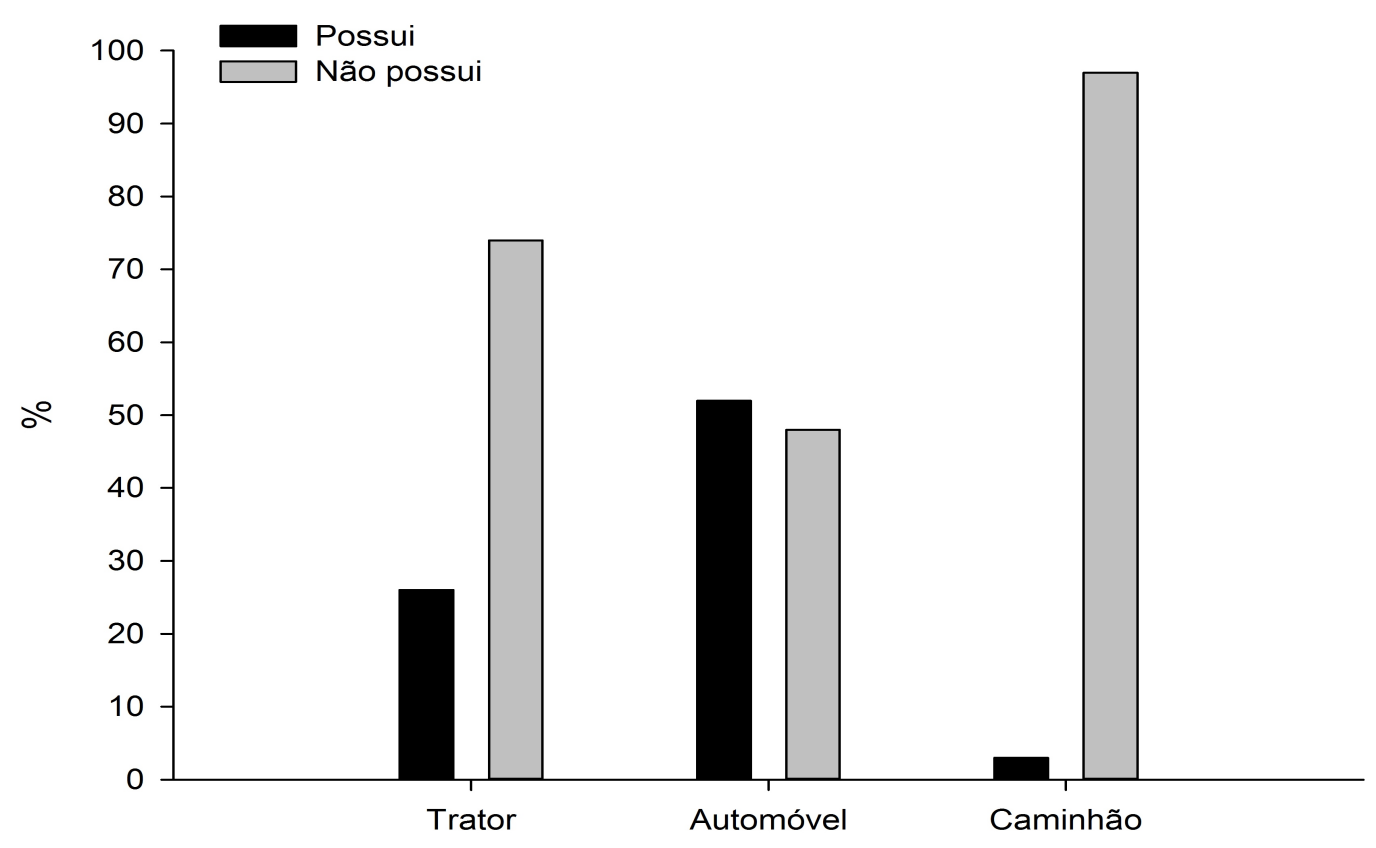

FIGURA 2 Percentagem dos produtores familiares do município de Taquaruçu do Sul que possuem equipamentos motorizados.

Da totalidade de produtores entrevistados, $74 \%$ desses não possuem tratores, isso pode ser explicado pela predominância de pequenas propriedades na região do Médio Alto Uruguai, o terreno declivoso dificulta a adoção desse tipo de veículo em trabalhos rurais. Outro fator deve-se a incerteza e riscos assumidos ao investir em um bem de alto valor, levando em consideração o custo-benefício deste bem em pequenas áreas de terra onde irá ser utilizado. Com essa realidade, muitas propriedades que não possuem esse nível estrutural acabam utilizando a terceirização de serviços de mecanização (trator ou caminhão). O caminhão para escoar a produção agrícola é pouco presente nesse cenário devido principalmente à produção ser em pequena escala nessa região, e na maioria das vezes tornando-se inviável sua aquisição.

GAZOLLA (2004) ao realizar um estudo na região do Alto Uruguai notou que o a presença de tratores nas propriedades familiares era de menos de $1 \%$, e os maiores investimentos em mecanização das propriedades é em pequenos motores estacionários, trilhadoras e outros equipamentos de menor porte. Se comparados com os dados dos gráficos houve um relevante aumento no número de equipamentos tratorizados, no entanto devido as condições de relevo da região, o uso de equipamentos mais antigos ainda é alto e é de grande importância para a agricultura praticada na região. 


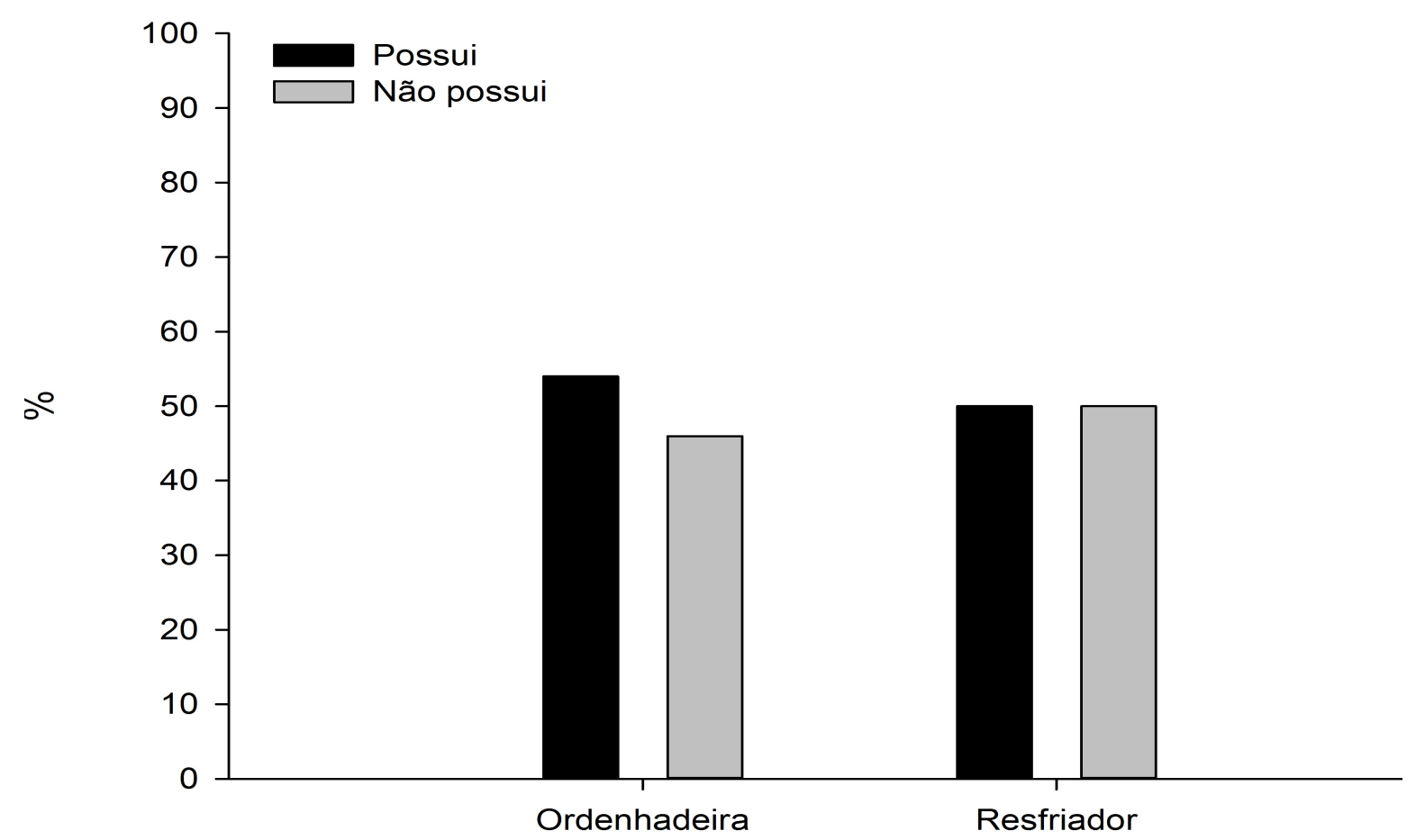

Equipamentos para atividade leiteira

FIGURA 3 Percentagem dos agricultores familiares que possuem resfriadores e ordenhadeiras mecanizadas na atividade leiteira, no município de Taquaruçu do Sul.

Na Figura 3, pode-se observar que em 54\% das propriedades a ordenha é feita mecanicamente, no entanto, apenas $50 \%$ dessas possuem resfriadores de leite. Sendo assim, pode-se inferir que apesar do setor leiteiro ser de extrema importância para a economia da agricultura familiar, há pouco investimento em infraestrutura e equipamentos que facilitam o trabalho e agregam qualidade e valor ao leite produzido.

A cadeia produtiva do leite no Brasil de forma geral ainda vem se adequando a um novo modelo que foi implantado a partir dos anos 90 , deixando aos poucos 0 modelo até então existente que tinha características rudimentares com uma produção baixa, pouca assistência técnica aos produtores entre outros fatores, sendo que alguns destes ainda persistem neste modelo, porém, com restrições devido as mudanças estruturais na cadeia produtiva que visam atender as novas demandas e exigências do mercado consumidor (SILVA et al., 2012).

Essas mudanças ocorreram em um espaço de tempo consideravelmente curto o que fez com que os pequenos e médios produtores tenham sido obrigados a se adequarem à nova realidade para se manter no mercado, sendo este um dos fatores que explicam a falta de equipamentos adequados e a desuniformidade nas propriedades, o que acaba dificultando a utilização desses equipamentos.

No que se refere a idade dos implementos pode-se observar a maior parte dos arados de tração animal tem entre 0 e 10 anos de uso (44,9\%) (Figura 4). A segunda parte estão com idade entre 11 e 20 anos de uso $(21,8 \%)$. Os arados de ENCICLOPÉDIA BIOSFERA, Centro Científico Conhecer - Goiânia, v.11 n.22; p.2136 2015 
tração mecânica possuem idades entre 0 a 10 e 11 a 20 anos de uso, ambos com $26,7 \%$.

Arados de tração animal

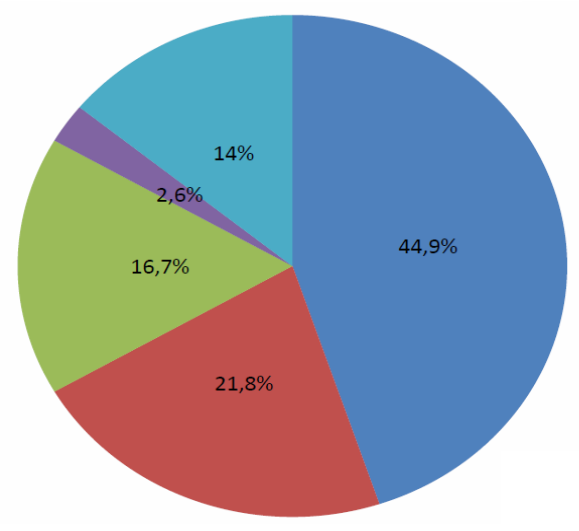

Arados de tração mecânica

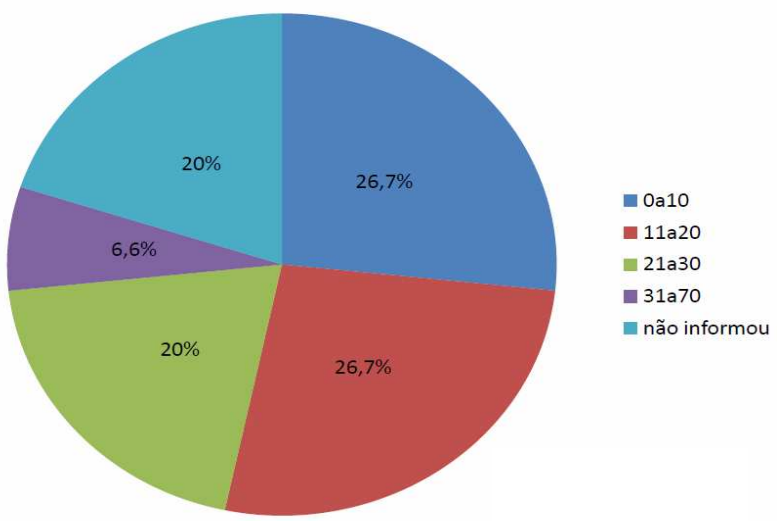

FIGURA 4 Idade média, em anos, dos arados de tração animal e mecânica de agricultores familiares do município de Taquaruçu do Sul.

Na Figura 5, pode ser observada a idade média dos equipamentos utilizados para a produção leiteira. Os resfriadores, em sua grande maioria, ou seja, $77,4 \%$ possuem entre 0 e 10 anos de uso. Resultado semelhante foi encontrado nos resultados das ordenhadeiras, $77,2 \%$ possuem entre 0 e 10 anos de uso, o que demonstra que essa tecnologia foi implantada recentemente na atividade leiteira. $O$ uso de tal tecnologia vem sendo impulsionada pela demanda das indústrias e consumidores por um produto de qualidade, além de buscar melhor qualidade de vida e mais comodidade no desempenho da atividade leiteira.

Idade média dos resfriadores de leite

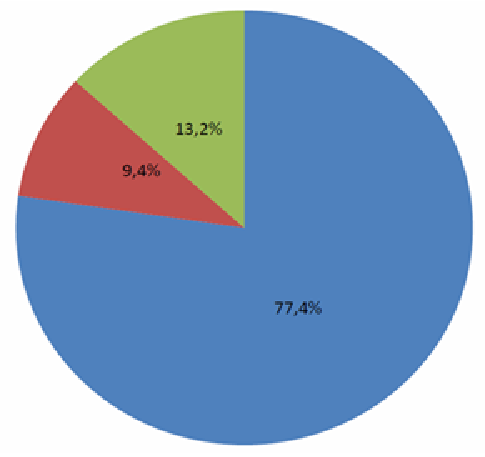

Idade média das ordenhadeiras

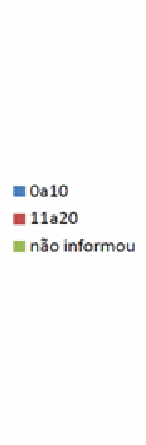

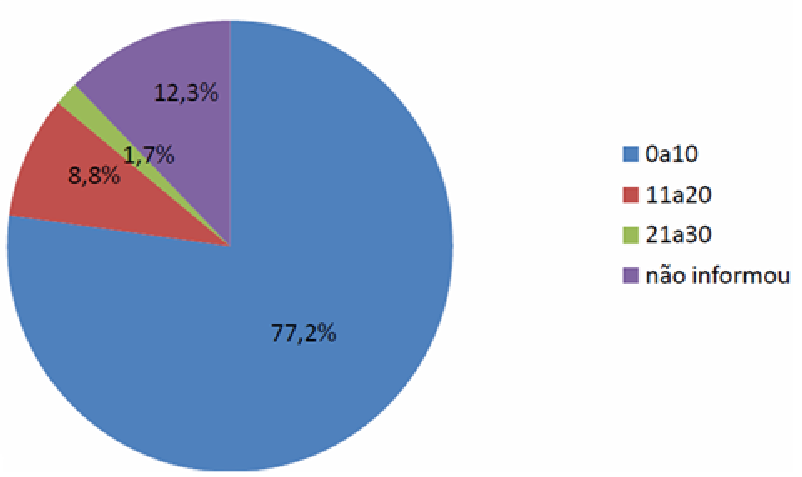

FIGURA 5 Idade média, em anos, dos principais equipamentos utilizados na produção leiteira de agricultores familiares do município de Taquaruçu do Sul.

Antes da atividade leiteira, a região se caracterizava como sendo produtora de commodities, fazendo com que muitos produtores tivessem que abandonar 0 
campo, ou mudar de atividade. Contudo, a atividade leiteira vem colaborando para a permanência do agricultor no campo, pois garante renda fixa mensal que se adquire com a venda do produto. Além de demandar menor número de terras agricultáveis para exercer essa atividade, proporciona um alto valor agregado pela quantidade produzida.

$\mathrm{Na}$ Figura 6, estão expressas as idades médias dos tratores utilizados nas atividades agrícolas da região. A Maior parte dos tratores $(39,3 \%)$ possuem idade entre 21 e 30 anos, $21,5 \%$, com idade entre 11 e 20 anos e 17,8\% com idade entre 0 e 10 e 31 a 40 anos de uso. Os veículos com idade entre 11 e 20 anos representam $34,5 \%$, seguido de $27,3 \%$ com idade entre 0 e 10 anos, $16,4 \%$ com idade entre 21 a 30 anos de uso e 17,8\% idade entre 31 e 40 anos. Esses resultados demonstram que os equipamentos utilizados na atividade agrícola dessas propriedades são rudimentares, e que por esse fato sejam de baixa tecnologia e comodidade para os operadores.

Idade média dos tratores

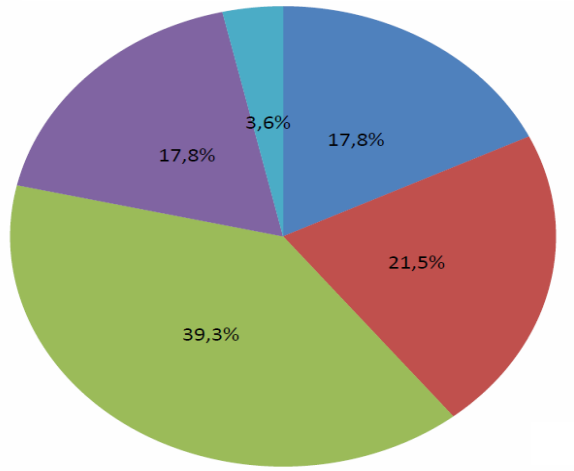

Idade média dos veículos

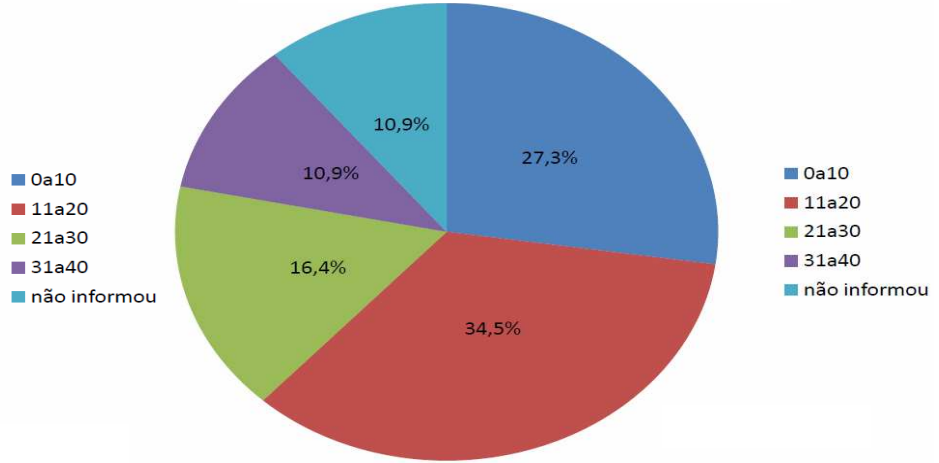

FIGURA 6 Média de idade, em anos, dos tratores e dos veículos de agricultores familiares do município de Taquaruçu do Sul/RS

Esses equipamentos por serem antigos nas propriedades, acabam gerando um gasto maior, fazendo com que o produtor perca em eficiência operacional, aumentando custos. $O$ fato da produção nas pequenas propriedades ser de pequena escala, e a atividade não depender totalmente disso, torna os tratores equipamentos com pouco retorno ao investimento.

Segundo SAVOLDI \& CUNHA (2010) o primeiro incentivo para investimentos na agricultura familiar ocorreu em 1970. Muitos dos equipamentos adquiridos na época ainda são utilizados pelos agricultores. No entanto em 1996 foi criado o PRONAF (Programa Nacional de Fortalecimento da Agricultura Familiar), com o intuito de aumentar a capacidade produtiva das propriedades rurais, servido também como incentivo para a aquisição de novos maquinários.

\section{CONCLUSÕES}

Os pequenos agricultores têm dificuldades financeiras que os impedem de adquirir equipamentos modernos. Os equipamentos utilizados, mesmo que antigos, ainda são úteis nas atividades agrícolas da propriedade. Nota-se com tal trabalho que falta aos produtores incentivos financeiros.

Assim, com o presente estudo pode-se concluir que as propriedades analisadas, na sua maioria, possuem pouca tecnologia empregada em maquinários, fazendo uso expressivo de implementos de tração animal. 


\section{AGRADECIMENTOS}

Ao MEC pela concessão das bolsas para os integrantes do Grupo Pet Ciências Agrárias FW e à Emater do escritório de Taquaruçu do Sul, RS, pelo auxílio nas visitas às residências dos agricultores familiares e disponibilidade dos dados desse trabalho.

\section{REFERÊNCIAS}

BATALHA, M.O.; BUAINAIN, A.M.; FILHO, H.M.S. Tecnologia de gestão e agricultura familiar. Disponível em: http://www.ufersa.edu.br. Acesso em 25/08/2015. BERETTA, C. C. Tração Animal na agricultura. p. 14. São Paulo: NoBEL, 1998.

BRASIL. IBGE - Instituto Brasileiro de Geografia e Estatística. Censo 2010, Indicadores Sociais Municipais. 2010. Disponivel em: <http://www.ibge.gov.br/>. Acesso em: jan. 2015.

BRASIL - Ministério do Desenvolvimento Agrário - Mais Alimentos. Disponível em: http://www.mda.gov.br/sitemda/secretaria/saf-mais/sobre-o-programa. Acesso em 02 de setembro de 2015.

CIDADES BRASIL. Disponível em: http://www.cidade-brasil.com.br/municipiotaquarucu-do-sul.html. Acesso em: 08 de novembro de 2015.

CONAB. COMPANHIA NACIONAL DE ABASTECIMENTO. Custos de produção: safra de verão - safra 2006-2007. Disponível em:

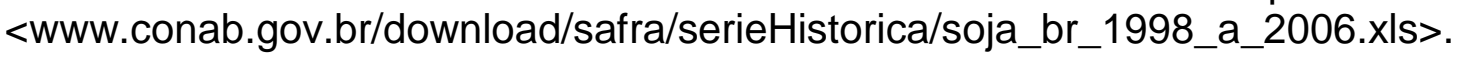
Acesso em: 09/11/2015.

EMATER, Empresa de Assistência Técnica e Extensão Rural. Mecanização Agrícola. Disponível em: http://www.emater.tche.br/site/area-tecnica/sistema-deproducao-vegetal/mecanizacao-agricola.php\#.VeOqZ_IVikp. Acesso em: 30 de agosto de 2015.

FILHO, H.M. S; BUAINAIN, A.M.; SILVEIRA, J.M.J; VINHOLIS, B.M.M. Condicionantes da adoção de inovações tecnológicas na agricultura. Cadernos de Ciência \& Tecnologia, Brasília, v. 28, n. 1, p. 223-255, jan./abr. 2011.

FILHO, H.M. S; BUAINAIN, A.M.; GUANZIROLI, C. Agricultura Familiar e Tecnologia no Brasil: características, desafios e obstáculos. Disponível em: http://www.researchgate.net/publication/266244829_Agricultura_Familiar_e_Tecnolo gia_no_Brasil_caractersticas_desafios_e_obstculos. Acesso em: 09 de novembro de 2015.

GAZOLLA, M. Agricultura Familiar, Segurança Alimentar E Políticas Públicas: uma análise a partir da produção para autoconsumo no território do Alto Uruguai/RS. Dissertação (Mestre em Desenvolvimento Rural) - Universidade Federal do Rio Grande do Sul, Porto Alegre, 2004. 
IBGE, Instituto Brasileiro de Geografia e Estatística. Censo agropecuário 2006: Disponível em: <http://www.ibge.gov.br/home/estatistica/economia/agropecuaria/ce nsoagro/agri_familiar_2006/familia_censoagro2006.pdf> Acesso em: 30 de agosto de 2015.

NEVES, L. A.; MACHADO, A. L. T.; REIS A. V.; Patrulha agrícola: uma alternativa de mecanização na agricultura familiar. Revista Varia Scientia Agrárias. v. 03, n.01, p. 59-75. 2013.

OLIVEIRA, M. G. C., PEREIRA, R. M. Importância da mecanização na agricultura familiar brasileira. Clic News, EMBRAPA. Outubro de 2010.

SILVA, G.; SILVA, A.M.A.D.; FERREIRA, M.P.B.; Processamento de leite. Setor de Processos Técnicos da Biblioteca Central - UFRPE, Recife, 2012.

MUNDO EDUCAÇÂO. Disponível em: http://www.mundoeducacao.com/geografia/agricultura-familiar.htm. Acesso em: 08 de novembro de 2015.

SAVOLDI, A.; CUNHA, L. A.; Uma abordagem sobre a agricultura familiar, PRONAF e a modernização da agricultura no sudoeste do paraná na década de 1970. Revista Geografar. Curitiba, v.5, n.1, p.25-45, jan./jun. 2010. 